\title{
Learning disability in the accident and emergency department ${ }^{1}$
}

\author{
Elspeth Bradley \& Jodi Lofchy
}

Abstract Generally, people with learning disabilities now live in community settings and use generic health services. Those who develop behavioural or psychiatric disturbances may be taken to a hospital accident and emergency (A\&E) department. An A\&E visit can be the starting point of a comprehensive assessment of these disturbances. This article provides a framework for the initial assessment, management and disposition of patients with learning disabilities and behavioural disturbance presenting to an A\&E department.

People with learning disabilities are now living more visibly in the community and using mainstream health services. Those with behavioural and psychiatric disturbances who previously would have been admitted to institutions are now accommodated by mobilising community supports.

Behavioural and psychiatric disturbances in learning disability are often complex aetiologically, requiring time and an interdisciplinary perspective for their full understanding and optimal intervention and outcome. Although access to specialist learning disability mental health services may be generally available in the UK, this is not the norm in other parts of the world (e.g. the USA, Canada and Australia). Many mental health crises are predictable and preventable (Levitas \& Gilson, 2001), but in the absence of needed generic and specialist community supports, situations escalate and come to the attention of the emergency services; the accident and emergency $(A \& E)$ department is one service within

1. This article is based on a teaching resource developed by E.B. and colleagues (including Lillian Burke, Caroll Drummond, Marika Korossy, Yona Lunsky and Susan Morris) for psychiatry residents at the University of Toronto (Bradley, E. A. \& Psychiatry Residency Year 1 University of Toronto Intellectual Disabilities Psychiatry Curriculum Planning Committee, 2002). E.B. and J.L. thank the copyright holders (Bradley, Korossy \& Morris) and the publishers (Centre for Addiction and Mental Health Publishers) for permission to reproduce sections of this teaching resource. the system of community supports (Grossman et al, 2000; Sullivan et al, 2000).

Emotional and behavioural disturbances in an individual with a learning disability may be a symptom of a 'system in crisis' (e.g. inappropriate expectations made of the individual or inadequate supports) rather than a symptom of psychiatric disorder. This distinction should determine the focus of immediate and longer-term interventions and ensure that the person is appropriately treated for any underlying disorder and not inappropriately medicated for behaviours that are communicating absent or inappropriate supports.

\section{Triage}

In general A\&E departments, patients are triaged according to urgency and perceived need: e.g. medical, surgical, psychiatric. A large proportion of referrals for psychiatric assessment is for management of agitation/aggression and behavioural problems (Table 1). Although moderate, severe and profound learning disabilities (Table 2) are likely to be recognised, staff unfamiliar with the communicative patterns of people with learning disabilities, across the spectrum of functioning, may not recognise additional mental and health disorders (the phenomenon of diagnostic overshadowing), attributing the behavioural disturbances to the learning disability. The learning disabilities of

Elspeth Bradley is Psychiatrist-in-Chief, Surrey Place Centre, Postgraduate Education Coordinator for Intellectual Disabilities, and Associate Professor in the Department of Psychiatry, University of Toronto (Surrey Place Centre, 2 Surrey Place, Toronto, Ontario, Canada M5S 2C2. Tel.: 416925 5141; fax: 416923 8476; e-mail: e.bradley@utoronto.ca). She is also senior consultant to the intellectual disabilities mental health service at the Centre for Addiction and Mental Health, Toronto, and Hamilton Health Sciences, Hamilton, Ontario. Dr Bradley trained in the UK and has been practising in Ontario for the past 13 years. Jodi Lofchy is the Director of Emergency Services, University Health Network in Toronto, Director of Undergraduate Education and Associate Professor in the Department of Psychiatry, University of Toronto. She has been involved in the development of formal teaching programmes in emergency psychiatry at the University of Toronto and has assisted other universities in the creation of similar programmes. 
Table 1 Differential diagnosis of aggression/agitation and approaches to treatment

Cause of aggression/agitation

Health problem

Pain and/or injury

Medical illness

Medication side-effects

Seizures

Dental problems

Supports, expectations and communication Inappropriate expectations/inadequate support Inability to express needs

Avoidance of an uncomfortable circumstance

To obtain positive reinforcers

Emotional concerns

Loss and/or bereavement

Disappointment

Adapting to change

Unexpected changes

Bullying or assault

Task-related anxiety

Difficulties modulating affect

Psychiatric disorders

Reflecting irritability secondary to mania,

depression or organic mental syndrome

Associated with psychotic experiences

(e.g. hallucinations, delusions)

\section{Action}

Identify and treat

Identify and treat

Review medications

Seizure and medication review

Dental consultation

Identify needs and adjust support

Assist with communication; teach alternative ways to express needs; provide alternative ways to get positive reinforcers

Identify current circumstance causing emotional upset; anticipate situations that may cause upset; provide appropriate support (e.g. arrange counselling, teach the patient anger management and ways to calm, environmental alteration, anticipatory planning)

Identify disorder and treat as required people with borderline and milder levels of cognitive impairment and of those with comorbid autisticspectrum disorders may or may not be recognised (Box 1). Psychiatry staff may be called to consult only if A\&E staff have questions regarding behavioural problems, issues associated with medical procedures, compliance with treatment, or the assessment of capacity and obtaining consent. Sometimes people with learning disabilities have relatively good social and communicative skills that mask significant deficits in other areas (a 'cloak of competence'), which gives rise to inappropriate expectations being made of them (such as following a treatment regimen without support).

\section{Table 2 Skills, abilities and living circumstances associated with severity of learning disability}

Severity of disability ${ }^{1}$

Borderline

$\mathrm{IQ}=70-84$, mental age $<11$ years

Mild

$\mathrm{IQ}=50-69$, mental age $=9$ to $<12$ years

Moderate

$\mathrm{IQ}=35-49$, mental age $=6$ to $<9$ years

Severe

$\mathrm{IQ}=20-34$, mental age $=3$ to $<6$ years

Profound

$\mathrm{IQ}<20$, mental age $=<3$ years
Typical skills, abilities and living circumstances

Living independently; subtle communication difficulties; high-school 'drop-out' or in special education; difficulty keeping a job; receiving government assistance; at risk of being in an abusive relationship; faces challenges rearing children, particularly if social and economic resources are inadequate

Relative independence in self-care; can hold a conversation and engage in the clinical interview; information provided may not be accurate; requires varying levels of service support; may have paid employment

Basic communication skills present; requires supervision with self-care; living in a group home; in a structured day programme or workshop

Communication difficulties; motor difficulties; requires greater supervision in daily activities; living with family or in a 24-hour staffed group home/nursing home; in alternative day programmes with a combination of skills-based and recreational activities

Requires 24-hour supervised care; living either with family or in group home/nursing home; has multiple medical problems; inner world largely unavailable to others because of communication difficulty

1. See Royal College of Psychiatrists, 2001: p. 18. 


\section{Box 1 Autism alert}

One-quarter to one-third of people with learning disabilities meet criteria for autism. Comorbid autism contributes to even more atypical clinical presentations than learning disability alone and also to difficulties in treatment. The combination of alexithymia-type difficulties and concrete thinking may give rise to bodily experiences being described in unusual ways and this can be mistaken for psychotic disorder, rather than a communication about a physical ailment or emotional distress. Consider autistic-spectrum disorder if:

- an individual has multiple previous psychiatric diagnoses (e.g. psychotic disorder; schizophrenia and schizoaffective disorders; schizoid, borderline and immature personality disorders; intermittent explosive disorder; anxiety disorder; attention-deficit hyperactivity disorder; obsessive-compulsive disorder), which often started in the teenage years and have shown little positive response to treatment

- there is a history of challenging behaviours, serious aggression, people getting hurt and high burnout of care staff

- there are previous diagnoses or descriptions of autism, autistic traits or childhood schizophrenia (hospital, school, psychological reports)

- there is a previous diagnosis of learning disability and schizophrenia/psychosis

- staff describe the person as being attention-seeking, manipulative or deliberately annoying/provoking and the family as being difficult or demanding

\section{Determining whether a patient has a learning disability}

If a patient's problems are thought to be psychiatric an appropriate evaluation is requested. From the point of entry for psychiatric evaluation, staff observe the patient broadly (watching actions and behaviour within the A\&E department), to determine competence/capacity and the level of risk for patient and staff, and more specifically (within the context of a more traditional mental state examination), to determine whether behaviour and symptoms may alert to the underlying cause of the mental distress. While it may be obvious that the patient has some kind of cognitive impairment, the cause of this has to be determined (Tables 3 and 4 ).

\section{Assessing patients with learning disabilities}

People with learning disabilities vary greatly in their ability to understand and communicate their needs, discomforts and concerns. During assessments psychiatrists therefore need to adapt their approach to each individual's level of functioning and understanding (Table 2 and Box 2). If the patient is behaving disruptively, begin by meeting briefly with the care providers to inquire about their client's level of functioning and to get advice on the best way to meet and interact with him or her. Find out about any circumstances that might be specifically upsetting for the patient (e.g. being asked too many questions; being in a noisy/busy environment; someone moving too close to them; seeing reflecting surfaces such as glasses). Many individuals are unable to communicate verbally but will be aware of non-verbal behaviours in others and are often sensitised to negative attitudes others have towards them. Some individuals depend on others to help modulate their emotions and will quickly pick up fear and anxiety in you. A warm, accepting, calm, reassuring attitude will help the patient feel more relaxed. Remember that appearances may be deceptive. Individuals with learning disabilities may appear to have a hearing impairment or to be mute when they are not. Overheard comments about them may exacerbate the presenting problems.

An A\&E department is generally a strange and unfamiliar environment for anyone. For people with learning disabilities, the experience may be particularly frightening because they may understand even less what is happening around them. Getting to A\&E may also have been traumatic, for both the person and the family or care providers. Waiting can be anxiety-provoking and contribute to behavioural disturbance. Take a moment to explain to patients and care providers the reason for the wait. If the wait is longer than you expected, reassure the patient from time to time. This will contribute to a more effective interview (see Box 2 for further suggestions).

Always check to see whether this is the person's first visit to $A \& E$ and whether there is an existing patient record. If the person has been to the department before, find out what worked and what did not. Find out if a proactive crisis plan has already been set up by care providers in the community and whether the care providers have brought a letter from the person's physician outlining this plan. It is 
Table 3 Screening for learning disability

Questions

\section{Early development}

What grade did you go to in school? How old were you when you left? Did you repeat any grades?

Did you attend special education classes? Were you identified as having special needs?

Were you in a regular or a modified programme?

Did you have a psychological assessment as a child at school or at a hospital? What did they tell you about the results?

\section{Current functioning}

Can you tell the time on a watch?

Do you travel alone on public transport? Did you come here by yourself today? What route did you take?

If you are going to a new place, do you need someone to show you how to get there?

Can you read the newspaper? What sections do you like the best? What is your favorite TV programme?

Do you look after your own money? Do you pay bills? Which bills? How do you pay them (by cheque, bank machine)?

How much does a cola and a bag of potato crisps cost? How much does a car cost? How much does a house cost?

Do you have a job? How many hours per week?

Do you have a job coach? Have you ever had a job? What did you do? Can you fill out a job application by yourself?

1. Adapted from the Surrey Place Centre Mental Health Team Protocol of 2004.
Sometimes dropped out of school early, sometimes extended schooling

May have attended school for special needs, or schooling was in special needs class

May know results of testing or if testing resulted in different schooling

Show the person your watch and ask what time it says: may be able to read digital but not watch with hands

Get the person to describe how they got to the appointment

Some can travel independently but journeys tend to be well-rehearsed routines; some have difficulty describing or planning new journey

Often will say that comics is favourite part, or that they can read only some of the paper

Ask them to describe what they do; most need assistance

Often will not be able to estimate well

Most often supported employment or sheltered workshop generally recognised that assessing a person who has a learning disability takes longer than the time required for someone without such disability.

\section{Biopsychosocial understanding}

The psychiatric assessment of people with learning disabilities involves systematic application of a biopsychosocial approach. Expect the presenting problems to have multiple and complex aetiological and contributing factors. Be systematic in taking a history. Be sure to assess the influence of causes other than psychiatric disorder for the referral concerns. The aim is to understand contributions from the following four factors.

\section{Medical disorders}

These include constipation, toothache, earache, reflux oesophagitis, bone fractures, urinary tract infection, other sources of pain or bodily discomfort.
Inquiry about vision and hearing should be made, as deterioration in sensory functioning can give rise to changes in behaviour.

Problems in expectations and supports: individuals with learning disabilities are much more dependent on external structures. Emotional problems often arise when expectations and supports change (e.g. a recent move; a change in staff - staff turnover can be very high in some group homes; a change in daily life schedule, such as start of school or work; a change in work activities) or are inappropriate (e.g. unrealistic expectations of completing tasks or travelling independently).

\section{Emotional upsets}

Behavioural change might be a response to a coresident or member of staff leaving the group home; to illness in the patient or a significant other; to trauma, abuse or triggers to past abuses; to a seasonal pattern/anniversary reaction; or to delayed grief. 
Table 4 Cognitive impairment and deterioration: checklist of causes and differential diagnosis in the A\&E

\begin{tabular}{|c|c|c|c|}
\hline Diagnosis & Description & History and collateral & In the $A \mathcal{E} E$ \\
\hline Learning disability & $\begin{array}{l}\text { Impairment resulting from } \\
\text { congenital cerebral injuries; } \\
\text { impairments present since child- } \\
\text { hood, relatively stable, accom- } \\
\text { panied by stigmata of cerebral } \\
\text { injury, e.g. syndrome, seizures }\end{array}$ & $\begin{array}{l}\text { Delay in development, may be } \\
\text { on a learning disability register, } \\
\text { recipient of learning disability } \\
\text { services in present or in past }\end{array}$ & $\begin{array}{l}\text { Dysmorphic features } \\
\text { (?syndrome), attends with care } \\
\text { provider, unable to give own } \\
\text { history, global delay in } \\
\text { functioning }\end{array}$ \\
\hline Dementia & $\begin{array}{l}\text { Intellectual deterioration affecting } \\
\text { several areas, including memory, } \\
\text { and interfering with occupational } \\
\text { and social functioning }\end{array}$ & $\begin{array}{l}\text { History of decline in cognitive and } \\
\text { adaptive functioning; may have } \\
\text { family history of dementia, medical } \\
\text { disorder associated with dementia. }\end{array}$ & $\begin{array}{l}\text { Neurological signs of dementia } \\
\text { and/or medical disorder } \\
1 \text { associated with dementia. } \\
\text { Administer the MMSE }\end{array}$ \\
\hline $\begin{array}{l}\text { Acute confusional } \\
\text { states (delirium) }\end{array}$ & $\begin{array}{l}\text { Impairment of consciousness } \\
\text { with intrusive abnormalities in } \\
\text { perception and affect caused by } \\
\text { acute organic pathology }\end{array}$ & $\begin{array}{l}\text { In children and elderly can } \\
\text { develop from a relatively minor } \\
\text { disturbance, e.g. dehydration }\end{array}$ & $\begin{array}{l}\text { Continuously changing clinical } \\
\text { picture, with acute to subacute } \\
\text { shifts; may be disoriented, } \\
\text { agitated, lethargic, inattentive. } \\
\text { Signs of systemic illness }\end{array}$ \\
\hline $\begin{array}{l}\text { Acquired } \\
\text { brain injury }\end{array}$ & $\begin{array}{l}\text { Normal development up until } \\
\text { brain injury, followed by deterior- } \\
\text { ation in functioning: may be global } \\
\text { or more discrete disability } \\
\text { depending on the cause and extent } \\
\text { of the brain injury. Causes include } \\
\text { physical trauma (e.g. car accident, } \\
\text { abuse) and cardiovascular events } \\
\text { (e.g. stroke) }\end{array}$ & $\begin{array}{l}\text { History of trauma followed by } \\
\text { change in functioning level; if } \\
\text { trauma occurred before } 18 \text { years } \\
\text { old may be receiving learning } \\
\text { disability services }\end{array}$ & $\begin{array}{l}\text { Neurological dysfunction, } \\
\text { usually specific deficits in } \\
\text { learning rather than global } \\
\text { delay. May be disinhibited, } \\
\text { inappropriate and show } \\
\text { mood lability }\end{array}$ \\
\hline $\begin{array}{l}\text { Mutism, stupor } \\
\text { and the apparently } \\
\text { inaccessible patient }\end{array}$ & $\begin{array}{l}\text { Caused by organic brain disorder, } \\
\text { physical illness, functional } \\
\text { psychiatric disorder (e.g. psycho- } \\
\text { motor retardation of depression; } \\
\text { catatonia associated with mood } \\
\text { disorder, schizophrenia and } \\
\text { autism; conversion hysteria) }\end{array}$ & $\begin{array}{l}\text { History of physical or psychiatric } \\
\text { illness, traumatic life event. } \\
\text { Determine the history to the time } \\
\text { of onset of the change in level of } \\
\text { consciousness or onset of mutism; } \\
\text { is this a familiar presentation } \\
\text { with decompensation? }\end{array}$ & $\begin{array}{l}\text { Unresponsive to usual social } \\
\text { and environmental stimuli; } \\
\text { signs of systemic illness, } \\
\text { delirium, physical or } \\
\text { psychiatric illness }\end{array}$ \\
\hline Autism & $\begin{array}{l}\text { Likely different causes, including } \\
\text { genetic predisposition. Impair- } \\
\text { ments in social interactions, verbal } \\
\text { and non-verbal communication, } \\
\text { ritualistic repetitive patterns of } \\
\text { behaviour. Covers the spectrum } \\
\text { of IQ from gifted to profound } \\
\text { learning disability }\end{array}$ & See Box 1 & $\begin{array}{l}\text { At higher levels of cognitive } \\
\text { functioning: one-sided social } \\
\text { and verbal interactions, com- } \\
\text { plex routines, manipulation } \\
\text { of objects; at lower levels of } \\
\text { cognitive functioning: hyper- } \\
\text { sensitivity to sensory stimuli, } \\
\text { abnormal movements, social } \\
\text { aloofness }\end{array}$ \\
\hline Other & $\begin{array}{l}\text { Other causes include medication, } \\
\text { abuse, sensory impairment } \\
\text { (deafness, visual impairment), } \\
\text { non-English speaking }\end{array}$ & $\begin{array}{l}\text { Taking cognition-altering } \\
\text { medication, recent immigrant }\end{array}$ & $\begin{array}{l}\text { May show medication toxicity } \\
\text { (e.g. drowsy, ataxic), fearful- } \\
\text { ness, watchfulness, injury } \\
\text { (trauma, abuse), may be } \\
\text { wearing hearing aid or respond } \\
\text { to non-verbal communication } \\
\text { (deaf) or another language } \\
\text { (non-English speaking) }\end{array}$ \\
\hline $\begin{array}{l}\text { Learning disability } \\
\text { and any of the } \\
\text { above as a } \\
\text { comorbid occurrence }\end{array}$ & $\begin{array}{l}\text { See text } \\
\text { ce }\end{array}$ & $\begin{array}{l}\text { First establish evidence for learning } \\
\text { disability and level of functioning, } \\
\text { then evidence for comorbid } \\
\text { disorder. Assess all behaviours } \\
\text { against baseline behaviour (usual } \\
\text { level of functioning) before } \\
\text { behaviour change. Consider } \\
\text { whether any other of the above } \\
\text { conditions are present }\end{array}$ & $\begin{array}{l}\text { Conduct examination with } \\
\text { care provider present and ask } \\
\text { them about current behaviour } \\
\text { compared with usual } \\
\text { behaviour. Screen for physical/ } \\
\text { medical disorder }\end{array}$ \\
\hline
\end{tabular}

MMSE, Mini-Mental State Examination. 


\section{Box 2 Interviewing patients with learning disabilities}

- Involve the patient as much as possible during the meeting. Talk to him or her directly rather than to care providers, unless the patient asks the care provider to help

- Explain the process of the meeting at the outset, using visual aids if needed

- Encourage the use of 'comforters', e.g. a favourite item the patient likes to carry or a preference for standing and pacing rather than sitting

- When talking about time events, locate these in the patient's experience

- Try to establish a positive relationship with the patient:

- be interested in a precious object the person is clutching

- show warmth and positive regard

- be sensitive to cues and tone of voice

- avoid direct questions: the patient may find these intimidating or may just say yes or no to please

- respect avoidance of eye contact

- test whether the patient prefers you not to use direct eye contact

- test whether the patient wants you to refer to him or her in third person (he, she, or name) rather than the second person (you)

- Find ways to communicate effectively:

- use simple words or phrases, short sentences

- speak slowly; do not shout; pause, do not overload the person with words; repeat questions if necessary; ask the patient to tell you in his or her own words what has been said

- be aware that the individual's expressive speech may give an impression of better comprehension than is actually the case

- be aware that some individuals may express themselves only in writing: test whether they want to

- use visual aids (e.g. drawings, picture books)

- use gestures

- Remember that people with learning disabilities have a variable and sometimes limited ability to interpret their own internal cues and may not be able to give you an accurate picture of their internal state. Involving care providers who know the patients well may help you better understand their subjective experiences

- If investigations are needed:

- ask permission to proceed before any intrusion of personal space

- explain and warn the patient about what to expect from procedures that may need to be done immediately

- ask care providers whether individual care plan/protocols have already been established for some procedures (e.g. venipuncture) and follow these

- provide reassurance during the procedure

Episodic/new-onset psychiatric disorders and non-episodic background conditions

Adjustment, mood, anxiety and post-traumatic stress disorders are the most frequent new-onset psychiatric disorders. Autism is the most frequent comorbid psychiatric disorder across the range of functioning. Stereotypies and self-injurious and compulsive behaviours are often seen as background comorbid conditions, especially in lower-functioning individuals.

In determining the relative contributions of the above four factors, all the basic areas of enquiry need to be examined: the patient's and care provider's main concerns; history of concerns with an emphasis on recent life events and changes; medical history; medication history; allergies; family psychiatric history; personal, developmental and social history.
More detailed information on the patient's usual level of functioning and supports prior to this episode of disturbance is needed. Further information on the following six areas should be sought:

- cognitive functioning: levels of reading, writing and numeracy; school history; results of previous psychological assessments; information about verbal and non-verbal IQ/ functioning

- adaptive functioning: level of independence in daily life skills - amount of support needed for hygiene, dressing, eating and preparing meals; whether the person can initiate his or her own activities, be left safely alone at home, travel independently

- communication: level of receptive understanding and expressive language 
- social functioning: e.g. the use of gesture to communicate and abnormalities in social response, eye contact, facial expression, social initiation and reciprocity that might indicate a co-exisiting autistic-spectrum disorder

- residential circumstances, e.g. whether living with family or in a group home, and level of support in these settings

- daily activity: e.g. whether attending school, a day centre or involved in other organised activities, and supports in pursuing these.

One goal of this inquiry is to determine whether expectations of the person, and the supports provided, are appropriate given the person's level of functioning and recent circumstances. For example, if there is a hearing or visual impairment, have appropriate adaptations been made in the physical and social environment?

In summary, assessing people with learning disabilities involves not only a standard psychiatric assessment, but also a systematic approach designed to identify the contribution of other circumstances to the behaviours of concern. In the A\&E department, it may be possible to get only a superficial understanding in these areas of inquiry, but this may be sufficient to alert to areas of concern that might be contributing to the problems and that need to be pursued in more detail by the multidisciplinary team once the immediate crisis is past.

\section{Assessing for episodic (new-onset) psychiatric disorders}

It is important first to determine whether there has been a substantial change in baseline behaviours and functioning. An episode (or episodes) of changed behaviour can be identified as follows (Bolton \& Rutter, 1994). First, determine usual/ baseline behaviour (prior to onset of new disturbance) in the areas of: self-care, interest/involvement in school/work, play/leisure, social involvement, initiative and level of supervision required. Second, determine whether (a) there has been a change in behaviour outside the range of normal variation for the individual, lasting at least 1 week, and a definite diminution in level of functioning in at least two of the six areas outlined above or (b) psychotic symptoms (e.g. delusions, hallucinations, catatonia) are, or have been, present and have lasted at least 3 days. (Note that it is difficult to diagnose psychotic symptoms in people with an IQ below 50.)

\section{Provisional psychiatric diagnosis}

If the referral concerns meet the criteria for change, then an episode of psychiatric disturbance is established. The next step is to try to match this episode to a psychiatric diagnosis in accordance with DSM-IV-TR (American Psychiatric Association, 2000), ICD-10MR (World Health Organization, 1996) or DC-LD (Royal College of Psychiatrists, 2001). This is frequently difficult, particularly for lower-functioning individuals, as subjective experiences needed to establish such a diagnosis may be unavailable. From the clinical information available, the best provisional diagnosis for any episodic psychiatric disorder should be generated.

\section{Assessing for non-episodic background conditions}

Baseline self-injurious behaviours, tics, stereotypies, obsessive thoughts and compulsive behaviours, levels of attention, hyperactivity, impulsivity, fears and phobias should be documented, as these may represent comorbid chronic conditions. Ask whether there have been any changes (an increase in severity and/or frequency) in these comorbid conditions associated with the referral concerns. Documenting whether any comorbid condition is present at this stage is crucial, as these conditions may also arise from the side-effects of psychotropic medications used to manage the crisis or to treat an underlying psychiatric disorder (see Box 3 for further cautions in $\mathrm{A} \& \mathrm{E})$.

\section{Risk assessment}

Risk of violence and suicide is part of every A\&E assessment and needs to be documented clearly in the history, mental status and final impression. The care provider is a valuable source of information about a patient's recent dangerous behaviour to self or others that would necessitate a hospital admission for further psychiatric assessment.

\section{Interventions in $\mathrm{A} \& \mathrm{E}$}

Assessing for psychiatric disorder in people with learning disabilities presents many challenges and requires obtaining detailed historical information as well as a multidisciplinary approach. This includes drawing not only on the perspective of psychiatry, but also on input from other disciplines, such as psychology, communication therapy, behavioural therapy, nursing, genetics and medicine, including neurology.

This diagnostic process can start in the A\&E department but, as already stated, definitive psychiatric diagnoses at this time should be avoided. Instead, careful documentation of whatever history 
is available, along with observations of behaviour and response to interventions should be made and this documentation passed on to the team to whom the patient is referred for further psychiatric assessment. The A\&E department provides an important opportunity to rule out possible medical disorders underlying the behaviours of concern and also the opportunity to observe the person in a more structured environment.

\section{Managing the immediate situation}

The first priority is to ensure the safety of the patient, care providers and hospital staff, consistent with the usual A\&E protocols. Only then can the assessment continue. Pharmacological or physical restraint may be required as with other people in crisis. A general approach to the management of aggressive or agitated patients in the A\&E department is outlined below. Modifications are required for patients with learning disabilities that depend on the nature of their disability (e.g. people with autism may show idiosyncratic responses to standard interventions) and level of cognitive and communicative functioning. For example, the more A\&E staff appreciate the patient's level of functioning and unique ways of communicating (either from direct observation and interaction or from reports from care providers), the more likely the escalation in aggression or agitation will abate and the less likely that excessive medication or restraint will be needed.

\section{Dealing with aggression and agitation}

Assessing aggressive or agitated patients is one of the most anxiety-provoking aspects of emergency psychiatry. Recognising early the progressive stages of agitation and aggression and intervening appropriately is a skill that is an essential part of training. Agitation and aggression occur along a continuum and will progress unimpeded unless you intervene to de-escalate the situation (Box 4).

\section{Box 3 Cautions}

Understanding changes from usual baseline behaviours

Behavioural changes may result from medical or dental disorders, problems in expectations or supports, or emotional upsets. It is important to understand the contribution (if any) of such circumstances to the behavioural disturbance before making a psychiatric diagnosis or concluding that the problem is psychiatric.

Understanding aggression

Aggression is often the reason for the visit to A\&E. The multitude of aetiologies giving rise to aggressive behaviours is outlined in Table 1 . The severity of the aggression does not necessarily indicate the seriousness of the underlying cause giving rise to the aggression.

Diagnostic limitations in AEE

The A\&E department is not the place to make definitive psychiatric diagnoses; however, provisional diagnoses based on clearly documented descriptions of behavioural changes can be made. The assessing psychiatrist should indicate clearly in the $A \& E$ evaluation/assessment report that the diagnosis is provisional and needs to be reviewed when the crisis has abated. This is necessary as a diagnosis made from a brief assessment can stick for years or even decades, and can result in the person being prescribed inappropriate medication for lengthy periods with considerable morbidity. Recommendations should include a clear outline of plans for follow-up and re-evaluation of the diagnosis and treatment.

Diagnosing psychosis

Psychotic-type behaviours in people with learning disabilities result more often from overwhelming life events than from an actual psychotic disorder. For example, if there is limited cognitive function at baseline, stress can fragment thought form in a way that may appear psychotic or the person may express primitive thoughts that sound delusional, but actually relate to poor coping more than to frank psychosis. If the patient is overwhelmed, treatment involves identifying and attending to the causative life events. However, if there is true psychosis, then antipsychotic treatment is required.

Note: in emergency presentations medication and other interventions may be required for immediate containment, even if no psychosis is diagnosed. It is therefore important that the evaluation/assessment report clearly states that medication was used to manage an emergency and that it does not imply a diagnosis. The report should also include an outline of specific plans for follow-up diagnostic appraisal, so that the need for medication can be reassessed. The use of chemical restraint to manage the crisis must be differentiated from actual treatment of any underlying disorder. 


\section{Box 4 Approaching agitated or aggressive} patients

The usual stages of violence and the appropriate intervention are as follows:

Stage

Intervention

1 Anxiety or agitation Ensure safety of patient and staff

2 Verbal threats

3 Overt aggression Verbal de-escalation

4 Resolution Physical interventions Medication

The situation may be different for patients with learning disabilities:

- they may behave atypically: for example, attempts to de-escalate the situation verbally may worsen the patient's agitation

- care providers often have an effective protocol and recommendations for managing out-ofcontrol behaviour in their clients; ask about these and use them if this can be done safely

- approaches in Box 2 generally help to engage the patients and avoid further escalation

- at each stage of your interaction with the patients make use of the care providers' knowledge and experience of their clients

Before you begin any assessment, you should observe the patient to determine the level of agitation and talk with the care providers to benefit from their knowledge and experience in dealing with the client. The setting in which you conduct your interview needs to be safe. An anxious or agitated patient may be pacing and need more space than the tiny interview room allows. The noise and stimulation of an A\&E waiting room may be further distressing, so it is helpful to triage quickly to a quiet interview room equipped with safety features such as video cameras, silent alarm buzzers, staff in close proximity, fixed furniture and two exit doors. Encourage the care provider to remain present, as he or she is likely to calm the patient and will probably be able to guide you in interacting with the client. You should feel comfortable in asking for a team member or psychiatric assistant to be in the room with you during your assessment. Make sure that both you and the patient (and care providers) can easily leave the room. Call periods of 'time out' if at any point you are concerned. Before you take the patient into the room, look for potential weapons - both on yourself and in the room. Ties, identification tags hanging from the neck and dangling jewelry should not be worn during psychiatric assessments. The room should contain no unfixed objects such as rubbish bins or telephones.
If police brought the patient to hospital, you should clarify if handcuffs were necessary. It is not recommended to assess patients wearing cuffs, as such restraint often makes it difficult to engage with them and develop a trusting relationship. If the patient is too agitated to be assessed safely without handcuffs, you should replace them with the medical equivalent - mechanical restraints. The police can help you and your team in transferring the patient from cuffs to restraints (and care providers may also be able to advise about effective ways to engage with the patient during this transfer).

Agitated patients may settle when you speak calmly, softly and with respect (even if they do not understand what you are saying): 'Mr. Brown, I am sorry you are upset... I kept you waiting... I would like to help... Can you tell me what is upsetting you?' Suspicious patients may need specific reassurances about safety: 'We are here to help you... You are safe here... [Name of care provider] is here... He/she will stay with you'. If verbal threats become more evident, you may need to use verbal de-escalation to help the patient. However, some people with learning disabilities, particularly those with greater cognitive impairment and coexisting autistic-spectrum disorder, respond negatively to the usual verbal deescalation procedure so, wherever possible, familiar de-escalation routines described by care providers should be used.

The patient may be unable to sit down and may be physically intimidating. You should not make yourself vulnerable by sitting when the patient is towering above you. If the patient is unable to sit, you should stand as well and gently attempt to set limits while still trying to understand what is of concern: 'You seem to be upset and are talking loudly... Let's see if we can both speak more slowly and softly ... and we can both try to relax'. There is opportunity here to model the behaviour desired, for example by speaking more slowly and quietly and moving into a more relaxed body posture and relaxation routine. You should not make sustained direct eye contact with the patient, especially if he or she is paranoid. A non-threatening stance, angling your body away from the patient, is preferable. If the patient's behaviour continues to escalate, you should anticipate overt aggression and be vigilant about potential assault. At this point, you will be making decisions about the type of physical intervention - mechanical and/or chemical restraint.

Once the anger is spent, the resolution phase is one in which you can often re-engage with the patient to explain what will be happening next, for example admission to hospital, police involvement and so on. 
The patient's agitation and aggression can move very quickly from one stage to the next and it may be almost impossible to de-escalate the situation when the patient is not able to hear you and appreciate the meaning of your reassurances. You will have to think quickly and be observant for signs of anxiety, cognitive disintegration, psychosis and disinhibition quite early in the assessment process. Physiological signs of anxiety, ataxic gait, incoherent or slurred speech and response to internal stimuli are all signs that the patient is distracted and may not be able to respond to your preliminary interventions.

If you need immediate assistance you may choose to call for extra specialist help. In Canada this is known as a 'code', an urgent request for extra staff trained in de-escalation procedures and comfortable using mechanical and chemical restraints for safety. In other countries a psychiatrist on-call might fulfil this function. It is a good idea to have medication close at hand, even if you do not need to use it. Before the patient can be medicated, the safety of all (the patient, staff and anyone else present) must be established and the immediate area cleared of unsafe features (e.g furniture that can be thrown). If the patient is severely agitated, it is preferable to secure him or her in mechanical restraints before giving the chemical restraint in an intramuscular dose. Highpotency antipsychotics (such as intramuscular haloperidol in combination with lorazepam, or oral risperidone with lorazepam) have less risk of lowering the seizure threshold, have a lower anticholinergic load and are required in smaller doses. Lorazepam diminishes the risk of acute dystonia in the A\&E, but the atypicals should be considered for long-term management. However, note that people with learning disabilities not infrequently show atypical responses to medications, which should therefore be used judiciously and with careful monitoring.

An episode of potential or actual violence is upsetting not only to the patient: care providers and A\&E staff are also affected and such an incident might predispose them to deny further contact with the patient or, by prejudging, to reject future patients with learning disabilities. There should be an opportunity to debrief and review the event with colleagues, so that the personal or professional distress experienced can be examined.

\section{Treating medical (and dental) disorders}

If there are suspicions that behavioural disturbance has physical/medical causes the patient should be referred for a medical assessment and treatment. Similarly, referral for dental check-up should be made if there are concerns about dental pain or discomfort or where dental care has not been provided routinely.

\section{Treating psychiatric disorder}

Once the crisis has been managed, if it has been determined that a psychiatric disorder probably underlies the behavioural disturbance, treatment can be initiated in line with the provisional diagnosis. A\&E staff should work with care providers to identify behavioural markers that can be monitored to substantiate or refute the provisional diagnosis. For instance, if the provisional diagnosis is a mood disorder, care providers can be instructed on collecting data on eating and sleep patterns, weight, and behavioural indicators of mood, anxiety, agitation and so on. Such documentation of a trial treatment started in the A\&E department is likely to be invaluable to the follow-up team to which the patient is subsequently referred.

\section{Changing medications}

Changing a patient's previous medications in this emergency situation should be avoided unless it is certain that they are contributing to the referral concerns. The temptation to prescribe the latest new medication just because it has not yet been tried for this person should be resisted; the A\&E team should limit their activities to dealing with the emergency and leave review of regular medication to the patient's usual treatment team. If the A\&E team feels strongly that an alternative medication regimen should be tried, this should first be discussed with the regular treatment team.

\section{Disposition}

\section{Where should further assessment and treatment take place?}

Consider what will be most helpful from the patient's perspective (e.g. need for familiarity during crisis). Also consider the goals of assessment and treatment, bearing in mind that care providers in community settings may be apprehensive about giving medication, monitoring side-effects and managing coexisting medical problems. Behavioural disturbance is frequently a symptom of a psychiatric disorder, and is an appropriate reason for admitting an individual for further observation.

Hospital admission

Sovner \& Hurley (1991) list a questions that should be asked if in-patient admission is considered:

- Is the person medically stable? If not, he or she is not suitable for a psychiatric in-patient unit.

- Is the person independent in activities of daily living or does he or she have sufficient 
expressive and receptive language skills to make any needs known? If not, can the referring agency, together with the hospital, provide daily support while the person is an in-patient?

- How will any aggressive, self-injurious or other behavioural problems be managed in an inpatient unit? Is additional support such as consultation from specialist services available?

- Are the treatment goals (e.g. clarification of diagnosis, stabilisation, review of medications) based on a provisional psychiatric diagnosis and are they realistic? Have symptoms and behaviours that might be monitored as indicators of response to treatment been identified?

- Is there an agreement with care providers that, on discharge, the person will return to where he or she was living before admission? If return to previous accommodation is not possible, have alternatives other than hospitalisation been discussed?

Be aware that some people show no evidence, in the $A \& E$ department or on the in-patient unit, of symptoms and behaviours described by their care providers. However, on leaving the structured environment of a hospital in-patient unit, these symptoms and behaviours reappear. This is valuable information that may only be obtained through admission.

If the person is admitted as an in-patient, consider how the trauma of admission can be reduced. Note that being admitted can be especially traumatic for lower-functioning people whose emotional and support needs may be similar to the needs of infants and young children. Care providers are often able and willing, with the support of their managers, to spend long periods with hospitalised clients.

\section{Non-hospital environments}

In the event of a situational crisis (e.g. loss of home, temporary inability of care providers to support an individual), options for crisis or respite services for people with learning disabilities may be available in the local community.

\section{Return to home environment with support}

Additional in-home or specialist supports for people with learning disabilities may be available locally.

\section{Follow-up}

\section{Medication}

If medication has been prescribed, the patient's GP and community psychiatrist should be informed. Those without a community physician should be connected to out-patient psychiatric services.

\section{Referral to specialist services}

Specialist assessment and consultation services may be needed where a coordinated interdisciplinary approach is necessary, for example if the situation is complex, if there is a history of difficulty clarifying a diagnosis or determining effective intervention, or if several services are already involved.

\section{Legal issues Informed consent}

The diagnosis of learning disability does not imply that the patient is incompetent to consent to treatment. Competence must be assessed on a caseby-case basis. Capacity to consent is a dynamic interplay of intellectual capacity (with some education about the issue and support in decisionmaking, a person with a learning disability may develop consent capacity) and emotional status (a patient who normally has capacity may no longer be able to consent because of overriding anxiety associated with being in the A\&E department). Also, the physician should be aware that an apparently competent patient may decline consent because of fear of a procedure associated with the treatment rather than declining the treatment itself (for further discussion of these issues see Heng \& Sullivan, 2003).

When issues of treatment and consent are being discussed with them, patients with learning disabilities are likely to benefit from the presence of care providers who can support their decisionmaking. If a patient clearly does not have the capacity to consent, an involved family member or long-term care provider should be asked to give consent on his or her behalf.

In an emergency, life-threatening problems warrant emergency treatment even in the absence of informed consent. Chemical restraint of competent but non-consenting patients is permissible if their mental disorder is leading to dangerous behaviour.

\section{Mandated reporting of abuse of disabled people}

Some jurisdictions have requirements that medical personnel report any suspicion of abuse.

\section{Guardianship}

If a legal guardian has been appointed, this person must give consent to any evaluation and treatment except in life-threatening situations. 


\section{Plan for next time}

As crises and coexisting health problems are not uncommon for many people with learning disabilities, care providers should be encouraged to develop a proactive crisis management plan. This should indicate clearly whom to call or what service to contact in response to the behaviours of concern. For example, for someone who experiences periods of disruptive behaviour, care providers should have available an escalation-hierarchy protocol that indicates how to respond to the individual at each point of his or her behavioural escalation, including when to go to the family doctor and when to take the person to an A\&E department.

It is often helpful for the care providers to have a letter written by the family physician or community psychiatrist that they can take with them to A\&E. This letter should briefly outline the psychiatric disorder and treatment being provided. The letter might also suggest preferred ways to manage general crises for that individual, based on past experiences. With each visit to $A \& E$ the crisis management plan should be updated. Care providers should also be encouraged to keep an individual file for A\&E visits and doctor's appointments and to bring this with them to the A\&E department.

It is important that recommendations from an A\&E visit are communicated (having obtained appropriate consent for release of information) to those supporting the individual in the community and, where appropriate, to those who may be involved in future crises (e.g. care providers, family members, community services). This can be done by giving a copy of the assessment and recommendations to the person accompanying the patient to the A\&E department and/or arranging for a copy to be sent to the care provider who sees the person daily and to the group home manager. These recommendations should be accompanied by a specific request that they be passed on to relevant family members, other care providers, the person's family doctor and psychiatrist. Where possible, A\&E staff should provide direct feedback to the person's community physicians.

\section{References}

American Psychiatric Association (2000) Diagnostic and Statistical Manual of Mental Disorders (4th edn, text revision) (DSM-IV-TR). Washington, DC: APA.

Bolton, P. \& Rutter, M. (1994) Schedule for Assessment of Psychiatric Problems Associated with Autism (and Other Developmental Disorders) (SAPPA): Informant Version. Cambridge \& London: University of Cambridge \& Institute of Psychiatry.
Bradley, E. A. \& Psychiatry Residency Year 1 University of Toronto Intellectual Disabilities Psychiatry Curriculum Planning Committee (2002) Guidelines for Managing the Client with Intellectual Disability in the Emergency Room, Toronto: Centre for Addiction and Mental Health.

Grossman, S.A., Richards, C.F., Anglin, D. and Hutson, H.R. (2000) Caring for the patient with mental retardation in the emergency department. Annals of Emergency Medicine $35,69-76$.

Heng, J. \& Sullivan, W. (2003) Ethical issues relating to consent in providing treatment and care. In Developmental Disabilities in Ontario (eds I. Brown \& M. E. Percy), pp. 727-735. Toronto: Ontario Association on Developmental Disabilities

Levitas, A. \& Gilson, S. F. (2001) Predictable crises in the lives of people with mental retardation. Mental Health Aspects of Developmental Disabilities, 4, 89-100.

Royal College of Psychiatrists (2001) DC-LD [Diagnostic Criteria for Psychiatric Disorders for Use with Adults with Learning Disabilities/Mental Retardation] (Occasional Paper OP 48). London: Gaskell.

Sovner, R. \& Hurley, A. D. (1991) Seven questions to ask when considering an acute psychiatric in-patient admission for a developmentally disabled adult. Habilitative Mental Healthcare Newsletter, 10, 27-30.

Sullivan, W., Berg, J. M., Bradley, E. A., et al (2000) Enhancing the emergency department outcomes of patients with mental retardation. Annals of Emergency Medicine, 36, 399400 .

World Health Organization (1996) ICD-10 Guide for Mental Retardation. Geneva: World Health Organization.

\section{MCQs}

1 Learning disability:

a is always recognised

b may appear as non-compliance with treatment

c may coexist with autism and other psychiatric disorders

d can give rise to atypical clinical presentations

e does not require modification of usual clinical approach.

2 In the A\&E department:

a information that care providers hold about their client is usually irrelevant

b definitive psychiatric diagnoses should be avoided

c clear plans for follow-up should be provided and communicated to care providers and the family doctor

$\mathrm{d}$ assessment and management have to be adapted to the patient's level of functioning

e previous aggressive behaviour may 'disappear'.

3 Psychotic-like behaviours in people with learning disabilities:

a usually indicate psychotic disorder

b may be associated with a medical disorder such as constipation

c may be associated with stress, e.g. if the patient has inadequate support or too much is expected of him or her

d may be made worse by antipsychotic medication

e can be better understood by a multidisciplinary team assessment. 
4 Aggressive behaviour in a person with a learning disability:

a may be related to an emotional concern, e.g. loss of care provider

b may be caused by a tooth abscess (or other physical discomfort)

c is best treated with medication

d may be understood by an analysis of the communicative function of the behaviour

e in the same person may have several different aetiologies.
5 Agitated patients with learning disabilities in the A\&E department:

a are never able to consent to taking medication

$\mathrm{b}$ require a thorough assessment of harm to both self and others

c are usually best managed by following the advice of the care providers on how to interact with their clients

$\mathrm{d}$ are best managed in an in-patient ward

e may settle with reassurance and supportive explanations about the assessment process.

\section{NEW OUT FROM GASKELL}

\section{A New Kind of Trainer}

\section{How to Develope the Training Role for People with Learning Disabilities}

\section{By Katherine Owen, Gary Butler and Sheila Hollins}

There is increasing expectation that service users will be involved in preparing health and social care professionals to work with people with learning disabilities, following a recommendation in the Government's White Paper Valuing People.

The Department of Mental Health - Learning Disability, at St George's Hospital Medical School, has been employing people with learning disabilities to train their medical staff for more than a decade. In this book, inspired by the Books Beyond Words series, they share their experience by giving information and advice to both people with learning disabilities who are interested in becoming trainers, and to organisations (particularly universities and colleges) who want to employ people with learning disabilities as trainers.

Illustrated by black and white photographs, the authors tell the story of a service user who is a training adviser. It describes how he got his job, what the job involves and how he continues to develop his role.

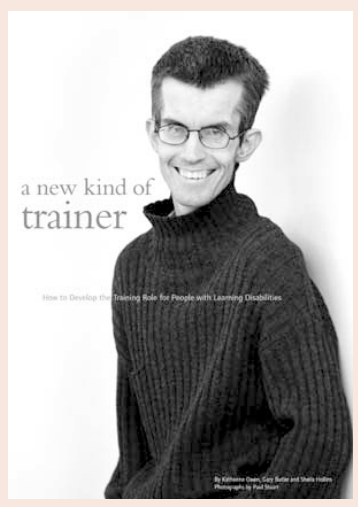

November 2004, A4 paperback, 64pp, ISBN 1904671 18 7, Price $£ 10.00$

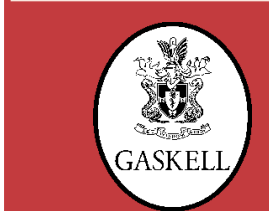

ORDER FROM: Book Sales, Royal College of Psychiatrists,

17 Belgrave Square, London SW1X 8PG, UK.

Tel: +44 (0)20 72352351 x146. Fax: +44 (0)20 72451231.

Website: www.rcpsych.ac.uk/publications 